\section{BLM Core Terrestrial Indicators and Methods}

\section{Technical Note 440}


August 2011 


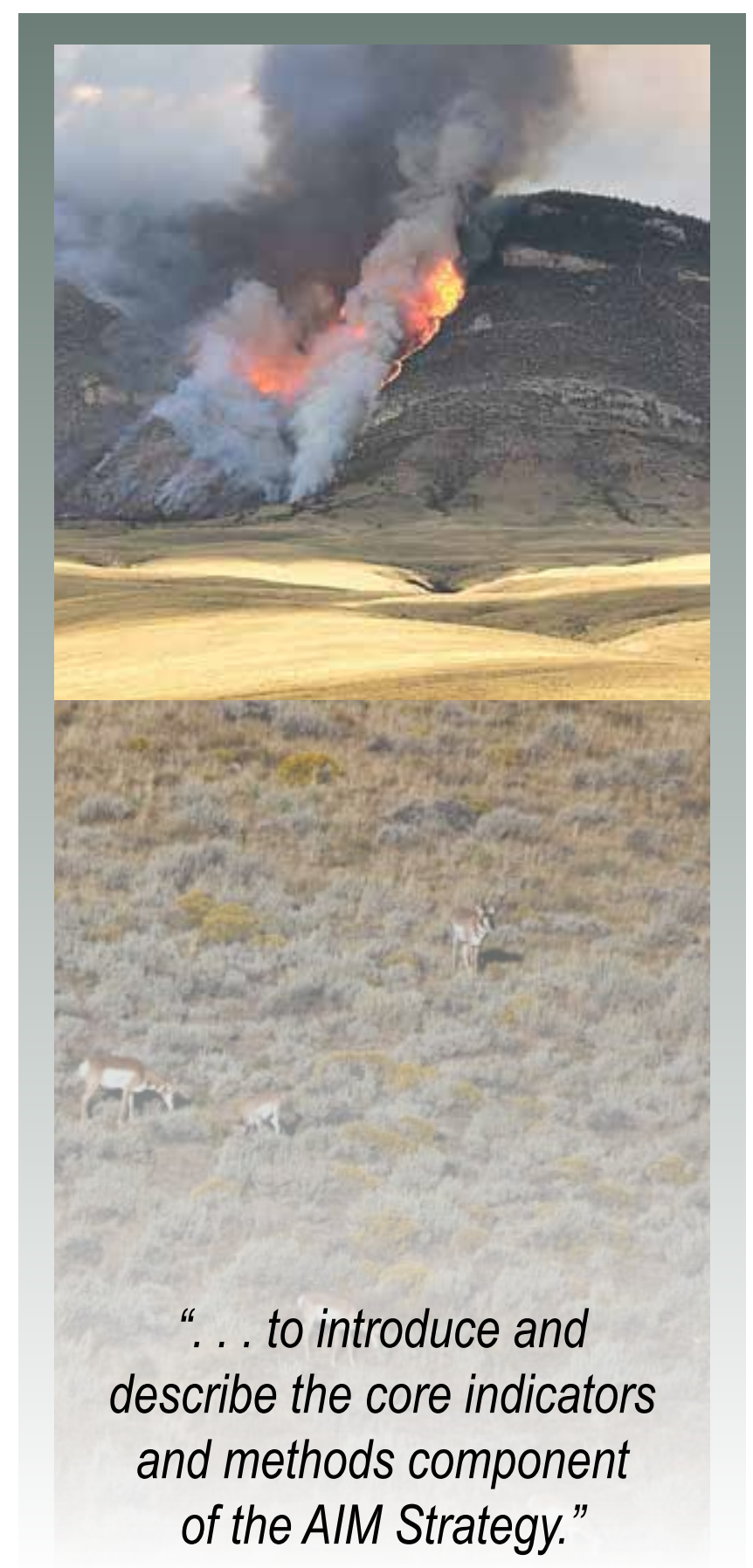

\section{Suggested Citation:}

MacKinnon, W.C., J.W. Karl, G.R. Toevs, J.J. Taylor, M. Karl, C.S. Spurrier, and J.E. Herrick. 2011. BLM core terrestrial indicators and methods. Tech Note 440. U.S. Department of the Interior, Bureau of Land Management, National Operations Center, Denver, CO.

\section{Production services provided by:}

Bureau of Land Management

National Operations Center

Information and Publishing Services Section

P.O. Box 25047

Denver, CO 80225 


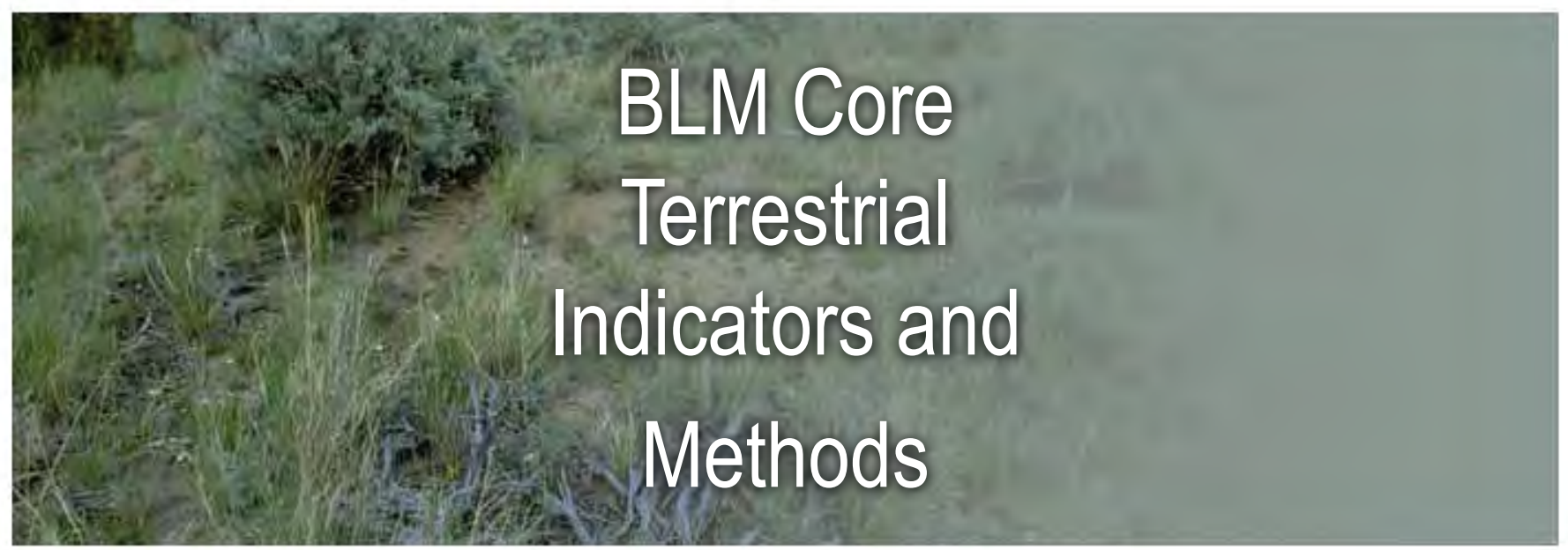

Technical Note 440

\section{Authors:}

W. Craig MacKinnon (retired), AIM Coordinator, BLM Washington Office, Washington, DC

Jason W. Karl, Research Ecologist, Agricultural Research Service-Jornada, Las Cruces, NM

Gordon R. Toevs, AIM Coordinator, BLM Washington Office, Washington, DC

Jason J. Taylor, Landscape Ecologist, BLM National Operations Center, Denver, CO

Michael "Sherm" Karl, Rangeland Management Specialist, BLM National Operations Center, Denver, CO

Carol S. Spurrier, Rangeland Ecologist, BLM Washington Office, Washington, DC

Jeffrey E. Herrick, Research Scientist, Agricultural Research Service-Jornada, Las Cruces, NM 







\section{Acknowledgments}

This technical report was prepared in cooperation with the U.S. Department of Agriculture, Agricultural Research Service (ARS), Jornada Experimental Range. This technical note is the result of a consultative process with significant support from Skye Wills with the ARS and Dave Pyke and Kate Kitchell with the U.S. Geological Survey (USGS). The following BLM employees participated in three multiday meetings during which they contributed to the development of the indicator selection criteria and the final selection of the indicators: Tim Bottomley, Bud Cribley, Roxanne Falise, Marty Griffith, Ted Milesnick, Kit Muller, Mike Pellant, and Doug Powell. Final indicator selection was based on analysis and interpretation of the results of a study in which more than 65 technical experts from the BLM, ARS, Department of Defense, Department of Energy, Natural Resources Conservation Service, USGS, and several universities applied the criteria to the indicators. The authors gratefully acknowledge these contributions. 


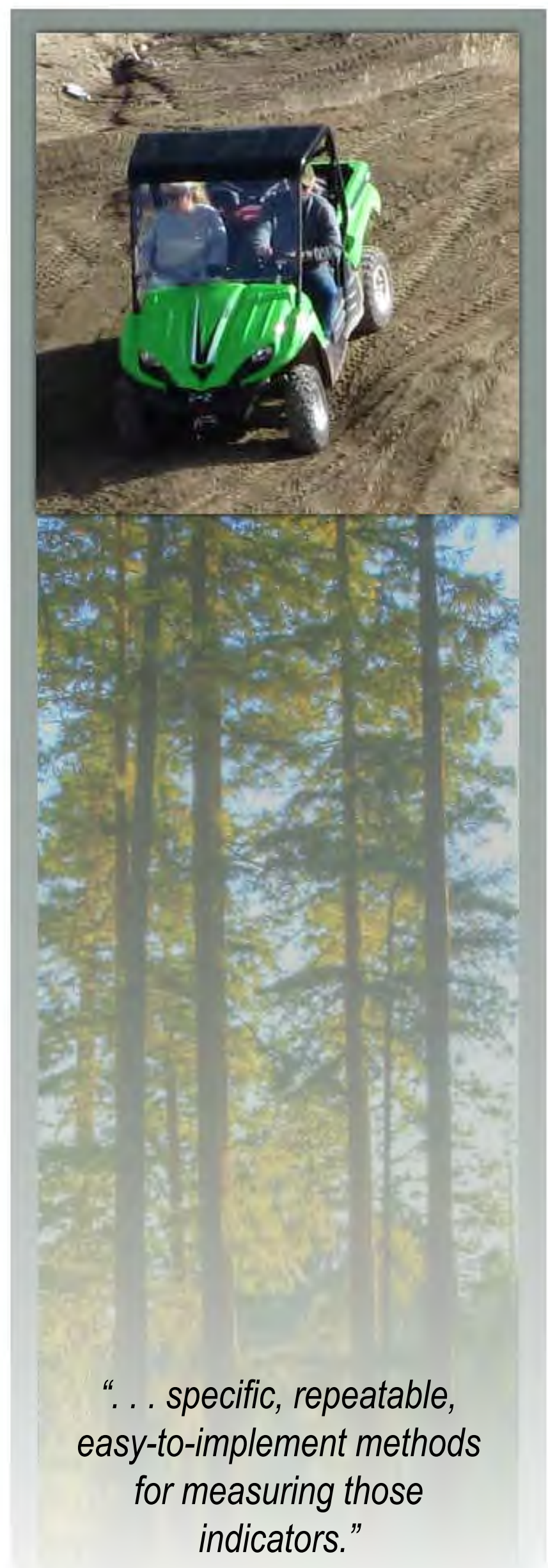




\section{Table of Contents}

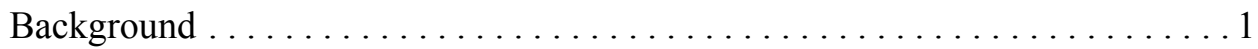

Terrestrial Indicators for the BLM. . . . . . . . . . . . . . . . 3

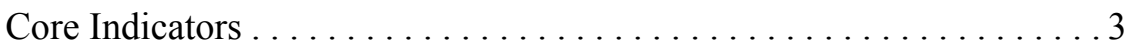

Contingent Indicators $\ldots \ldots \ldots \ldots \ldots \ldots \ldots \ldots \ldots \ldots \ldots$

Measurement Methods for the Core Indicators $\ldots \ldots \ldots \ldots \ldots \ldots \ldots$

Modifications of Recommended Methods and the Ability to Aggregate Indicators $\ldots \ldots \ldots \ldots \ldots \ldots \ldots$

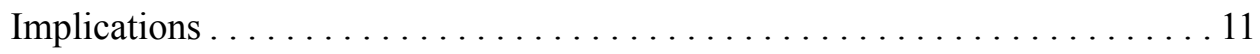

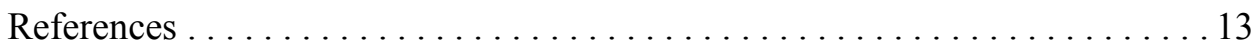






"The core indicators and methods provide a basis for obtaining high-quality data that can address many objectives. . ." 


\section{Background}

The Bureau of Land Management (BLM) Assessment, Inventory, and Monitoring (AIM) Strategy was initiated, in part, to evaluate current monitoring activities and recommend procedures to improve the efficiency and effectiveness of these activities. To this end, the AIM Strategy supports an integrated approach to: (1) document the distribution and abundance of natural resources on public lands; (2) facilitate the description of resource conditions; and (3) identify natural resource trends or changes. These objectives will be accomplished through the integration of fundamental processes including the: (1) development and application of a consistent set of ecosystem indicators and methods for measuring them (i.e., quantitative core indicators and consistent methods for monitoring); (2) development and implementation of a statistically valid sampling framework; (3) application and integration of remote sensing technologies; and (4) implementation of related data acquisition and management plans (Toevs et al. 2011).

The purpose of this technical note is to introduce and describe the core indicators and methods component of the AIM Strategy. Further, this technical note provides guidance on how to maintain consistency of effort and resources (i.e., cited materials) when needing further details on established protocols. This core indicators and methods component identifies a small set of core indicators (i.e., measurements) that, when collected, can be used for many purposes across ecosystem types including rangeland, forest, and riparian areas. This set of core indicators, based on quantitative land cover and vegetation data using standardized measurements, will allow data to be integrated across field, district, and state office boundaries.

Biotic integrity, soil and site stability, and hydrologic function have been identified as essential attributes necessary to describe ecosystem sustainability (see Figure 1). Foundational to the AIM Strategy is a suite of quantitative indicators related to these three attributes (i.e., what to measure) and specific, repeatable, easy-to-implement methods for measuring those indicators (i.e., how to measure them). The core indicators and methods adopted for AIM-related sampling represent a minimum set of information that should be

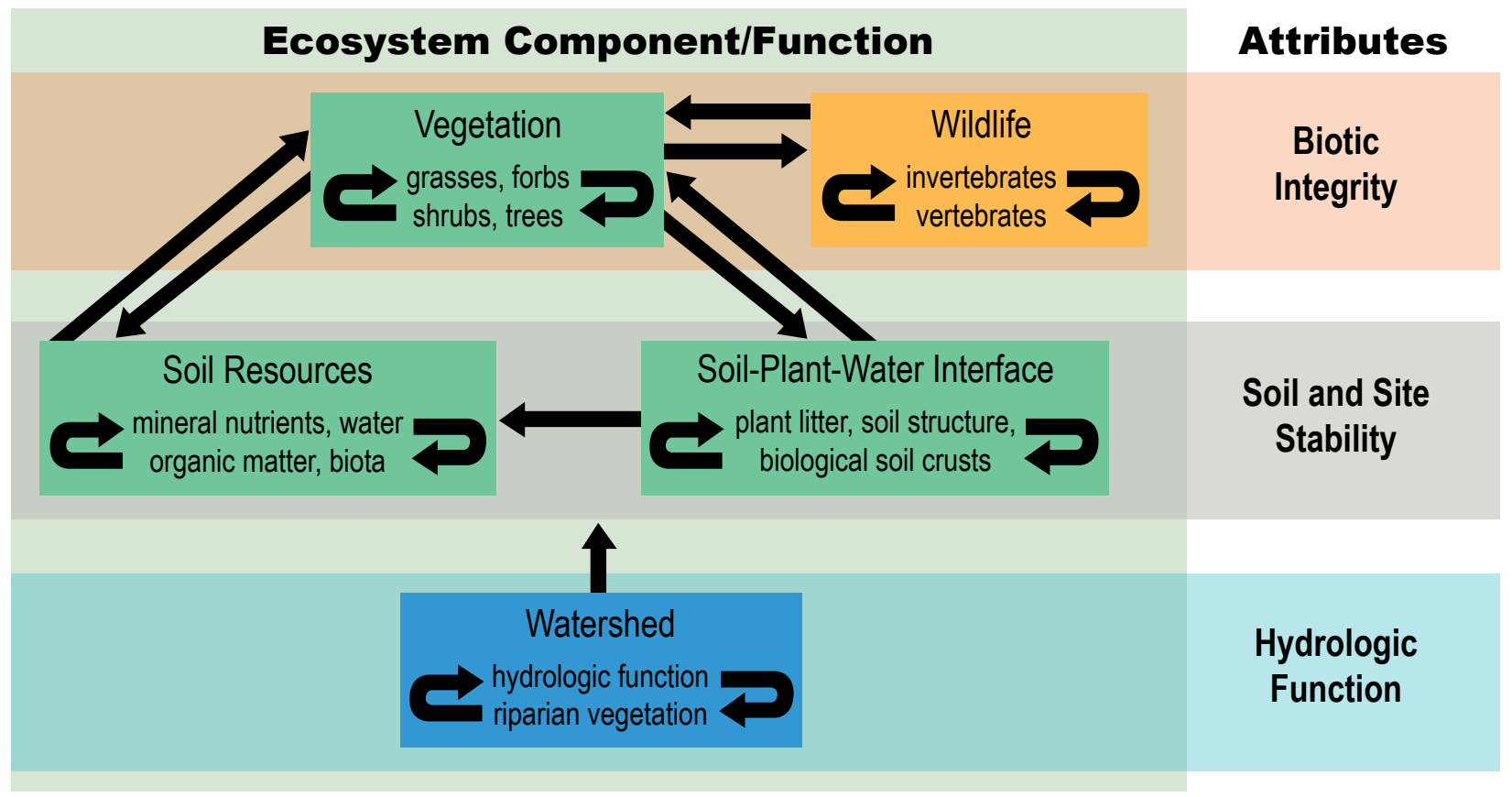

Figure 1. Assessing and monitoring natural systems requires consideration of the major structural components of ecosystems (boxes) and their functional relationships (solid arrows). Biotic integrity, soil and site stability, and hydrologic function have been identified as the three key attributes that can be evaluated to determine site integrity and the functional status of ecological processes (Pellant et al. 2005). This figure is adapted from Miller (2005). 
collected at each sample location. Contingent indicators and methods are implemented where necessary (see Table 1 and associated text). In order to meet local information needs related to management questions or specific ecosystem characteristics, the core and contingent indicators can be supplemented with additional indicators calculated from the core methods or, if necessary, from additional locally specific methods.

The core indicators and methods provide a basis for obtaining high-quality data that can address many objec- tives (e.g., vegetation and habitat management, change detection, and remote sensing needs). Additionally, datasets that are intended to address local management questions and collected using the core indicators and methods can be combined to meet needs at scales larger than the immediate monitoring area (e.g., for regional and national reporting). 


\section{Terrestrial Indicators for the BLM}

The AIM Strategy's indicators and methods were developed by a collaborative process involving nearly 200 scientists, rangeland managers, and ecologists from different agencies/institutions (Herrick et al. 2010). Participants rated an extensive list of potential indicators against 16 criteria, ultimately selecting the most general indicators with the broadest applicability to a range of management questions. Standard methods for measuring the BLM indicators were selected that met the following requirements: well documented, widely used, easy to implement, and minimal potential for bias.

Additional information regarding the selection of the indicators and methods is available in Terrestrial Indicators and Measurements: Selection Process and Preliminary Recommendations (Herrick et al. 2010), and guidance on statistically valid sample design for the indicators and methods is currently being developed. It is beyond the scope of this report to provide detailed instructions for implementing each of the core methods or to discuss intricacies of sample design. However, guidance is given on modifications for core and contingent methods that could affect the ability to combine data. Unless specific guidance is given, readers should see the referenced technical documentation, manuals, and training materials for protocols to implement the core and contingent methods.

\section{Core Indicators}

Six core indicators are recommended wherever the BLM implements quantitative vegetation and/or soil monitoring (see Table 1). These indicators were selected to meet BLM management needs, but they are widely accepted and generic enough to provide standardized data collection across jurisdictions (i.e., internally within the BLM, but also with other agencies and nongovernmental organizations). These indicators are:

(1) Bare ground. The amount of bare ground is widely accepted as one of the most sensitive indicators of resource condition in rangelands. A large percentage of bare ground can be an indicator of high erosion potential, low forage production, poor wildlife habitat, and increased risk of invasion by nonnative plant species. Also, where it appears in riparian and forest systems, a large percentage of bare ground is generally an indicator that the system has been significantly modified.

(2) Vegetation composition. Vegetation composition data, including the cover of groups of species, has historically been applied in some form in virtually every monitoring program across all cover types. Vegetation composition and cover indicators are generated from the same data, and when used together, it has been shown that they are sensitive to most changes in nearly every terrestrial ecosystem's status. In addition, the known vegetation composition is critical for determining the fire regime condition class, and the indicator (or group of indicators) is useful when determining the status of key species in plant communities that provide forage for all classes of herbivores.

(3) Nonnative invasive plant species. The presence and cover of nonnative species is acquired as a component of vegetation composition. Nonnative invasive species have the ability to significantly alter resource use sustainability, site resilience, disturbance regimes, or ecohydrology. Nonnative invasive species is also listed as a separate indicator because of its national, regional, and local management importance.

(4) Plant species of management concern. The presence and cover of plant species of management concern is also acquired as a component of vegetation composition. Plant species of management concern can be sensitive to site disturbance, provide important ecosystem functions, or contribute to biological diversity. Plant species of management concern is also listed as a separate indicator because it is specifically required for BLM reporting.

(5) Vegetation height. Vegetation height describes the vertical structure of vegetation, which can be used to characterize wildlife habitat and estimate wind erosion potential. When used together with the proportion of the soil surface in large intercanopy gaps (see core indicator 6), it can be used to create three-dimensional models of vegetation structure. 
(6) Proportion of soil surface in large intercanopy gaps. This indicator is necessary to estimate erosion potential and provides data that can be used together with vegetation height measurements to create three-dimensional models of vegetation structure, which are necessary for wildlife habitat characterization.

\section{Contingent Indicators}

Two contingent indicators are measured only when there is reason to believe problems that are related to either indicator exist on a site (see Table 1).

(1) Soil aggregate stability. This indicator reflects changes in soil erodibility and is sensitive to changes in soil organic matter cycling. It should be evaluated where a model (based on bare ground, average precipitation, and a broad soil texture class) predicts that stability is less than a minimum value. This model scenario describes most rangelands, except for well-managed, midto tall-grass prairie ecosystems. Making this indicator contingent ensures that time will not be wasted on measurements of highly stable soils.

(2) Significant accumulation of soil toxins. This indicator is important because it reflects major threats to human and environmental health. It should be evaluated where there is reason to believe that a significant accumulation of toxins exists. It was not included as a core indicator because (a) it is extremely expensive and would be difficult to measure with existing budgets, (b) it is likely to be near zero on the majority of BLM lands, and (c) in most cases it should be possible to predict where significant accumulations of toxins are likely to occur.

Table 1. Core and contingent indicators for the AIM Strategy and their collection methods. Core indicators are always measured. Contingent indicators are only measured if there is reason to believe they are necessary for monitoring or assessing the site.

\begin{tabular}{|c|c|c|c|}
\hline Type & Indicator & Method * & Where applied? \\
\hline \multirow{3}{*}{ Core: all locations } & $\begin{array}{l}\text { Amount of bare ground, } \\
\text { vegetation composition, non- } \\
\text { native invasive plant species, } \\
\text { plant species of management } \\
\text { concern }\end{array}$ & $\begin{array}{l}\text { Line-point intercept (including } \\
\text { modifications) supplemented } \\
\text { with plot-level species inven- } \\
\text { tory }\end{array}$ & All vegetation monitoring \\
\hline & Vegetation height & $\begin{array}{l}\text { Height at selected line-point } \\
\text { intercept points }\end{array}$ & All vegetation monitoring \\
\hline & $\begin{array}{l}\text { Proportion of soil surface in } \\
\text { large intercanopy gaps }\end{array}$ & Canopy gap intercept & All vegetation monitoring \\
\hline \multirow{2}{*}{$\begin{array}{l}\text { Contingent: where and } \\
\text { when necessary }\end{array}$} & Soil aggregate stability & Soil stability & $\begin{array}{l}\text { When soils are potentially } \\
\text { unstable (most rangeland) }\end{array}$ \\
\hline & $\begin{array}{l}\text { Significant accumulation of } \\
\text { soil toxins }\end{array}$ & Sampling for toxins in soil & $\begin{array}{l}\text { When toxins are believed } \\
\text { present }\end{array}$ \\
\hline
\end{tabular}

* For method descriptions, refer to Table 2. 


\section{Measurement Methods for the Core Indicators}

The need to monitor standard indicators to determine ecosystem condition is generally accepted. With this in mind, the BLM has adopted the aforementioned indicators to describe the condition of the three key ecosystem attributes (i.e., biotic integrity, soil and site stability, and hydrologic function). Data collected using the six core and two contingent indicators are appropriate to inform a wide range of management questions. However, the need for standardization of methods and rule sets for measuring the indicators is less accepted. Even so, standard methods are just as critical as a consistent set of indicators because minor differences between methods that provide similar types of information (e.g., cover, density) can make measurements incompatible.

An example of this is the difference between using foliar cover (i.e., actual exposed plant area) vs. canopy cover (i.e., area of influence of a plant) when measuring cover indicators (see Figure 2). For the same area, canopy cover measurements will be higher than foliar

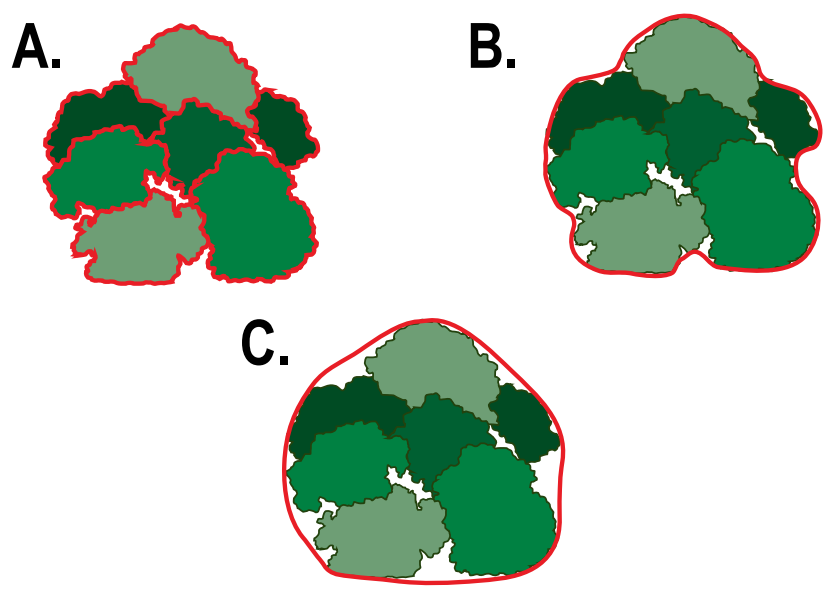

Figure 2. Example of a common difference in measuring plant cover that results in incompatible data. Foliar cover (a) measures just the exposed plant area, whereas total canopy cover (b) measures the area of influence of the plant. Relative to each other, the foliar cover method will produce lower estimates of plant cover and higher estimates of bare ground than will a total canopy cover method. Because the two methods are measuring different aspects of plant cover, estimates from the two methods cannot be combined. Canopy cover estimates are often biased by differences in how the canopy "margins" are defined (b vs. c) by different observers, or by the same observer at different times, or for different species or morphologies. cover. This could have implications when comparing two measurements collected using different rule sets, when trying to combine these data to make larger scale inferences, or when trying to use the data to train remotely sensed imagery. This example illustrates methodological differences that can affect the accuracy of measurements (i.e., the estimates derived from each method would be different). Other types of modifications, such as changing the number of measurements per plot, can often be made without affecting accuracy, though they may also affect precision (see Modifications of Recommended Methods and the Ability to Aggregate Indicators).

Adopting a consistent set of monitoring methods will allow the BLM to combine and compare data collected in different areas and data collected to address different objectives. The subsequent methods were selected based on the following requirements: well documented, widely used, easy to implement, and minimal potential for bias. Table 2 lists each method and the core and contingent indicators it measures, gives recommendations to achieve consistent implementation across the Bureau, and provides references describing each method's complete protocol. The protocols should be carefully followed in order to ensure that data collected from different areas can be compared or combined.

\section{(1) Line-point intercept (LPI) with plot-level species inventory}

Core indicators: bare ground, vegetation composition, nonnative invasive plant species, and plant species of management concern

LPI is a widely-used, rapid method for measuring vegetation and soil surface cover. Vegetation cover by species and soil surface type are measured by dropping a narrow pin (or pointer) at fixed intervals (i.e., points) along transects and recording all species that intercept the pin as well as the soil surface types where the pin touches the ground - modifications are suggested for data collection in tree cover (see Table 2). Precautions taken in standard LPI protocols contribute to it being one of the least biased of cover measures (Elzinga et al. 1998; Herrick et al. 2009). 
Table 2. Recommended methods and measurements for core and contingent indicators

\begin{tabular}{|c|c|c|c|}
\hline Method & Indicator(s) & Description & Reference(s) \\
\hline \multicolumn{4}{|l|}{ For core indicators } \\
\hline $\begin{array}{l}\text { Line-point intercept with plot-level } \\
\text { species inventory }\end{array}$ & $\begin{array}{l}\text { Bare ground, vegetation } \\
\text { composition, nonnative } \\
\text { invasive plant species, } \\
\text { plant species of } \\
\text { management concern }\end{array}$ & $\begin{array}{l}\text { Line-point intercept (LPI) is a rapid } \\
\text { and accurate method for quantify- } \\
\text { ing cover of vegetation and bare } \\
\text { ground. However, because LPI } \\
\text { can underestimate cover of un- } \\
\text { common species, this method is } \\
\text { supplemented with searches of a } \\
150-\text {-ft ( } 45.7-\mathrm{m} \text { ) diameter standard } \\
\text { plot for at least } 15 \text { minutes and } \\
\text { then searching until new spe- } \\
\text { cies detections are more than } 2 \\
\text { minutes apart. When performing } \\
\text { LPI within tree cover, a modified } \\
\text { pin method (e.g., a pivotable laser } \\
\text { or extendable pin) will be used to } \\
\text { capture overstory cover. }\end{array}$ & $\begin{array}{l}\text { NRCS (2009) for LPI and } \\
\text { species inventory, Herrick et al. } \\
\text { (2009) for LPI }\end{array}$ \\
\hline Vegetation height & Vegetation height & $\begin{array}{l}\text { Measure height of tallest leaf or } \\
\text { stem of woody and herbaceous } \\
\text { vegetation (living or dead) within } \\
\text { a } 6 \text {-in (15-cm) radius recorded for } \\
\text { points along a transect. If vegeta- } \\
\text { tion is taller than } 10 \mathrm{ft} \text {, a standard } \\
\text { tape and clinometer method } \\
\text { should be used to estimate veg- } \\
\text { etation height. }\end{array}$ & NRCS (2009) \\
\hline Canopy gap intercept & $\begin{array}{l}\text { Proportion of soil surface } \\
\text { in large intercanopy } \\
\text { gaps }\end{array}$ & $\begin{array}{l}\text { Canopy gap intercept measures } \\
\text { the proportion of a line covered by } \\
\text { large gaps between plant cano- } \\
\text { pies and is an important indicator } \\
\text { of the potential for erosion. Use } \\
1-\mathrm{ft}(30-\mathrm{cm}) \text { minimum gaps. }\end{array}$ & $\begin{array}{l}\text { NRCS (2009), Herrick et al. } \\
(2009)\end{array}$ \\
\hline \multicolumn{4}{|l|}{ For contingent indicators } \\
\hline Soil stability & Soil aggregate stability & $\begin{array}{l}\text { This test measures the soil's } \\
\text { stability when exposed to rapid } \\
\text { wetting and provides information } \\
\text { on integrity of soil aggregates, } \\
\text { degree of structural development, } \\
\text { resistance to erosion, and soil } \\
\text { biotic integrity. }\end{array}$ & $\begin{array}{l}\text { NRCS (2009), Herrick et al. } \\
(2009)\end{array}$ \\
\hline Soil sample collection & $\begin{array}{l}\text { Significant accumulation } \\
\text { of soil toxins }\end{array}$ & $\begin{array}{l}\text { The presence and concentrations } \\
\text { of toxins are assessed by collect- } \\
\text { ing three samples from the soil } \\
\text { surface and one sample at depths } \\
\text { of } 0 \text { to } 4 \text { in }(0 \text { to } 10 \mathrm{~cm}) \text { and } 4 \text { to } 8 \\
\text { in }(10 \text { to } 20 \mathrm{~cm}) \text { using a soil corer } \\
\text { and following the Forest Inventory } \\
\text { and Analysis protocol. }\end{array}$ & USFS (2007) \\
\hline
\end{tabular}


While LPI, when performed correctly, can provide unbiased estimates of cover for vegetation species, its precision is proportional to the number of points that are measured per plot location. For this reason, LPI can miss species that are uncommon or patchily distributed in a plot. However, on average, it will accurately estimate cover of all species. To address the "nonnative invasive plant species" and other "plant species of management concern" core indicators, LPI should be supplemented with a species inventory of a fixed-area plot. Plots need to be large enough to capture the full diversity of the site: $150-\mathrm{ft}(45.7-\mathrm{m})$ diameter circular plots are recommended to be compatible with National Resources Inventory (NRI) data.

Plots should be searched by one individual for at least 15 minutes, and then searching should continue until new species detections are more than 2 minutes apart. Searching should be done in such a way as to minimize soil surface trampling. Setting a minimum time limit on the searching within the plot ensures the plot is adequately sampled, and stopping when a specified time between new detections has been reached limits the additional cost of implementing the plot-level inventory and ensures the species list is a good estimate of actual diversity at the site.

\section{(2) Vegetation height}

\section{Core indicator: vegetation height}

The NRI vegetation height method used by the Natural Resources Conservation Service is a fast and unbiased way to measure vertical structure of vegetation. The NRI vegetation height method records the height and species of the tallest living or dead, woody and herbaceous vegetation within a small radius, $15 \mathrm{~cm}$ or approximately 6 in (NRCS 2009), of points at fixed intervals along the same transects as used for LPI.

Although vegetation height is not commonly quantified using remote sensing at the present time, data acquisition (e.g., LiDAR, Light Detection and Ranging, or stereo-pair imagery) and analysis (e.g., improved algorithms for LiDAR or automated stereoscopic tools for photographs) technologies already exist that will soon be ready for broadscale application.

\section{(3) Canopy gap intercept}

Core indicator: proportion of soil surface in large intercanopy gaps

Canopy gap intercept measures the proportion of a transect covered by large gaps between plant canopies. This field-measured indicator should be evaluated where at least one intercanopy gap longer than $30 \mathrm{~cm}$ is observed to exist on the transects used to measure bare ground and vegetation composition. This value will likely be zero in closed canopy forests and highly productive range and riparian sites. Note that a "zero" can have high value for baseline monitoring.

Canopy gaps are measured along the transect tape measure according to the NRI protocol (NRCS 2009) by recording the start and stop location of each gap above a minimum size. The length of each gap is calculated, and the sum of the lengths is divided by the transect length to obtain the proportion of soil surface in large intercanopy gaps. The minimum gap size, as well as what types of vegetation (e.g., shrubs, perennial grasses, annual grasses, forbs) are considered to be in the canopy (versus which are considered as part of canopy gaps), must be consistent for canopy gap measurements to be aggregated.

\section{(4) Soil stability}

Contingent indicator: soil aggregate stability

The soil stability test described by Herrick et al. (2009) and NRCS (2009) is a relatively simple method that measures the stability of soil when exposed to rapid wetting. This method yields information on soil structural development and resistance to erosion.

\section{(5) Soil sample collection}

\section{Contingent indicator: significant accumulation of} soil toxins

The presence and concentrations of toxins should be measured through standardized sampling of soils at a site. The U.S. Forest Service's Forest Inventory and Analysis (FIA) program includes a protocol (USFS 2007) for collecting samples at the soil surface and at two standard soil depths- 
0 to 4 in $(0$ to $10 \mathrm{~cm})$ and 4 to 8 in $(10$ to $20 \mathrm{~cm})$ - to test for accumulation of toxins. Under the FIA protocol, three soil surface samples are taken, and a single sample is taken at the other depths using a soil corer. Samples are not composited (i.e., multiple samples are not combined and mixed prior to analysis) between plots, but are composited within plots. 


\section{Modifications of Recommended Methods and the Ability to Aggregate Indicators}

To maximize the potential for aggregating measurements of the core and contingent indicators, the core methods should be implemented in the same manner throughout the BLM. The recommended methods are implemented in carefully prescribed ways in protocols like NRI and FIA to minimize variability (e.g., due to measurement error or differences between observers) and maintain the ability to aggregate data for regionaland national-level analyses. Occasionally, however, constraints exist that necessitate modification of the way the core and contingent indicator methods will be applied.

The core and contingent indicator methods can be modified in various ways, and depending on what is modified, the ability to aggregate data may or may not be affected. In general, modifying the definitions of what is recorded or how it is recorded will result in measurements that cannot be aggregated with other data because the meaning of the data is not consistent. For example, the line-point intercept method requires that a plant hit be recorded only if a raindrop would hit the plant part. Points that fall within the plant canopy but do not intercept a leaf or stem are not recorded.

Alternatively, data that have been collected using the same definitions but that vary with respect to aspects, like how many transects are sampled, the length of the transects, and the size of fixed-area plots, can be aggregated. Modifications like these affect only the within-plot variability, and while the variance of the measurements may be affected (which will affect the confidence of an assessment and the number of observations required to detect change), the meaning of the measurements has not been altered. Table 3 describes modifications that can and cannot be made to recommended indicator methods in order to preserve the ability to aggregate local data to larger scales. All modifications to the protocols must be documented in metadata, which always accompanies the collected data. 
Table 3. Modifications that can and cannot be made to recommended methods in order to preserve the ability to aggregate local data to larger scales

\begin{tabular}{|c|c|c|}
\hline M & n & What C \\
\hline $\begin{array}{l}\text { Line-point intercept with } \\
\text { plot-level inventory }\end{array}$ & $\begin{array}{l}\text { - Number and spatial distribution of transects }{ }^{\star} \\
\text { - Length of transects } \\
\text { - Number of points per transect } \\
\text { - Additional information about species at all points } \\
\text { or a subset of points (e.g., dead vs. live hit) }\end{array}$ & $\begin{array}{l}\text { - Foliar vs. total canopy cover (must use foliar) } \\
\text { - Definition of litter vs. standing dead (litter is de- } \\
\text { tached; standing dead is included in foliar cover) } \\
\text { - The minimum size of a rock fragment before it is } \\
\text { considered soil (i.e., rocks smaller than } 5 \mathrm{~mm} \text { or } \\
\text { about } 1 / 4 \text { in are considered soil) } \\
\text { - Size of fixed plot (circular plot of } 150-\mathrm{ft} \text { diameter } \\
\text { recommended) } \\
\text { - Amount of time a fixed plot is searched (searches } \\
\text { should be at least } 15 \text { minutes and continue until } \\
\text { new species detections are more than } 2 \text { minutes } \\
\text { apart) }\end{array}$ \\
\hline Vegetation height & $\begin{array}{l}\text { - Number and spatial distribution of transects* } \\
\text { - Length of transects } \\
\text { - Number of points per transect } \\
\text { - Number of species or functional groups for which } \\
\text { height is recorded (provided that tallest is always } \\
\text { recorded) }\end{array}$ & $\begin{array}{l}\text { which maximum height is } \\
5 \mathrm{~cm})\end{array}$ \\
\hline Canopy gap intercept & $\begin{array}{l}\text { - Number and spatial distribution of transects* } \\
\text { - Length of transects } \\
\text { - Minimum gap size can be decreased }\end{array}$ & $\begin{array}{l}\text { - Definition of canopy necessary to stop a gap (50\% } \\
\text { cover on any 0.1-ft (1.25-in or 3-cm) segment) } \\
\text { - The decision to include annual grasses and forbs } \\
\text { when interrupting a gap } \\
\text { - Minimum gap size cannot be increased } \\
\text { - What happens at beginning/end of transect (gaps } \\
\text { defined to ends of the transect only) }\end{array}$ \\
\hline Soil stability & $\begin{array}{l}\text { - Number of sampling locations within a plot } \\
\text { - Where samples are selected along transect (pro- } \\
\text { vided that it is systematic or random) }\end{array}$ & $\begin{array}{l}\text { - Whether or not subsurface samples are collected } \\
\text { (can help interpretation where surface disturbance } \\
\text { is common) } \\
\text { - Time thresholds for determining stability class } \\
\text { (see references in Table 2) }\end{array}$ \\
\hline Soil sample collection & $\begin{array}{l}\text { - Number of locations sampled within each plot } \\
\text { - Whether or not samples composited within plot } \\
\text { - Configuration of sample locations within plot } \\
\text { - Additional depths (greater than } 8 \text { in) or subdivision } \\
\text { of recommended depths }\end{array}$ & $\begin{array}{l}\text { Depths at which samples are collected (samples } \\
\text { should be collected at soil surface and at depths of } 0 \\
\text { to } 4 \text { in and } 4 \text { to } 8 \text { in) }\end{array}$ \\
\hline
\end{tabular}

${ }^{*}$ Transects should be independent (not contiguous or intersecting) 


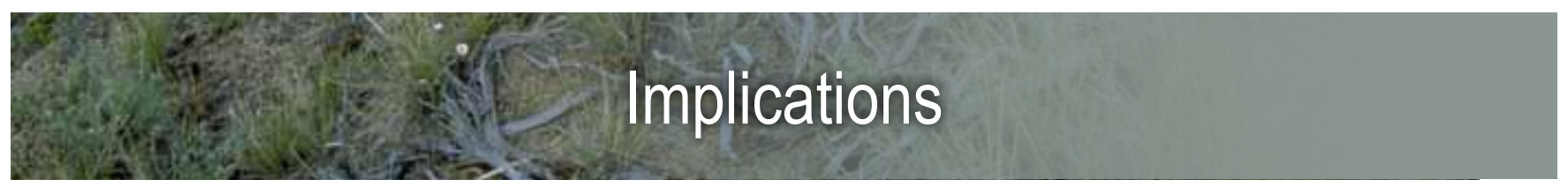

The AIM Strategy core indicators and methods are commonly used and easy to implement, and their application will help reduce error and increase compatibility of BLM monitoring efforts. They are generic enough to be accepted by a wide range of users and provide a variety of measures applicable to many different management objectives. The core and contingent indicators and associated methods can be supplemented by additional indicators to address local needs.

The rate of change and the increase in uses on public lands are at unprecedented levels. In order to make effective management decisions and respond to existing and emerging threats on public lands, robust monitoring and assessment programs that are capable of delivering actionable and defensible information must be implemented. Given resource constraints and the sheer number of monitoring needs, it is no longer possible to implement individual monitoring and assessment plans for each identified threat or use. Deriving the knowledge of how ecosystem conditions are changing, which is necessary to influence and justify management or policy action, necessitates consistent data that can serve many monitoring objectives and be aggregated for use across multiple scales. The core indicators and methods described here are the foundation for such a multiscale, multiobjective approach. 


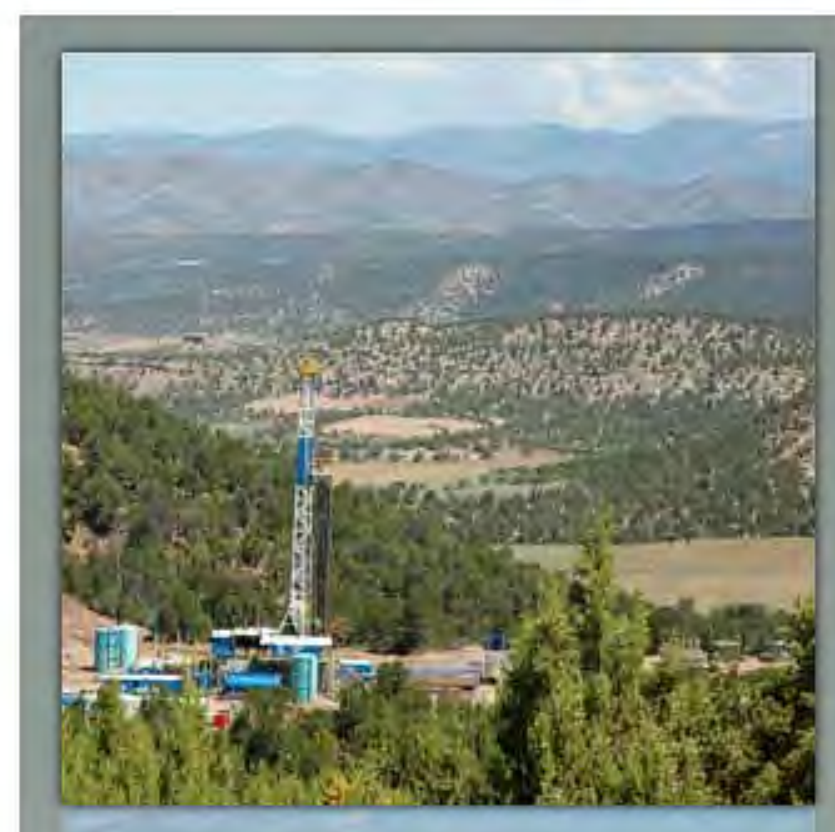

"In order to make effective management decisions and respond to existing and emerging threats on public lands, robust monitoring and assessment programs that are capable of delivering actionable and defensible information must be implemented." 


\section{References}

Ducey, M.J., and H.T. Valentine. 2008. Direct sampling for stand density index. Western Journal of Applied Forestry 23 (2): 78.

Elzinga, C.L., D.W. Salzer, and J.W. Willoughby. 1998. Measuring and monitoring plant populations. Tech Ref 1730-1. U.S. Department of the Interior, Bureau of Land Management, National Business Center, Denver, CO. http:// www.blm.gov/nstc/library/techref.htm.

Herrick, J.E., J.W. Van Zee, K.M. Havstad, L.M. Burkett, and W.G. Whitford. 2009. Monitoring manual for grassland, shrubland and savanna ecosystems. U.S. Department of Agriculture, Agricultural Research Service, Jornada Experimental Range, Las Cruces, NM.

Herrick, J.E., S. Wills, J. Karl, and D. Pyke. 2010. Terrestrial indicators and measurements: Selection process and recommendations. U.S. Department of Agriculture. http://jornada. nmsu.edu/sites/default/files/AIM_Terrestrial_ Indicators_Selection.pdf.

Miller, M.E. 2005. The structure and functioning of dryland ecosystems - conceptual models to inform long-term ecological monitoring. Scientific Investigations Report 2005-5197. U.S. Department of the Interior, U.S. Geological Survey, Reston, VA. http://pubs.usgs.gov/ sir/2005/5197/.
NRCS (Natural Resources Conservation Service). 2009. National Resources Inventory grazing land on-site study: Handbook of instructions. U.S. Department of Agriculture, Natural Resources Conservation Service.

Pellant, M., P. Shaver, D.A. Pyke, and J.E. Herrick. 2005. Interpreting indicators of rangeland health, version 4. Tech Ref 1734-6. U.S. Department of the Interior, Bureau of Land Management, National Science and Technology Center, Denver, CO. http://www.blm.gov/ nstc/library/techref.htm.

SRM (Society for Range Management). 1999. A glossary of terms used in range management. 4th Edition. Society for Range Management, Denver, CO.

Toevs, G.R., J.J. Taylor, C.S. Spurrier, W.C. MacKinnon, and M.R. Bobo. 2011. Bureau of Land Management Assessment, Inventory, and Monitoring Strategy: For integrated renewable resources management. U.S. Department of the Interior, Bureau of Land Management, National Operations Center, Denver, CO.

USFS (U.S. Forest Service). 2007. Forest Inventory and Analysis National Core Field Guide, Version 4.0. U.S. Department of Agriculture, U.S. Forest Service, Forest Inventory and Analysis National Office, Washington, DC. 


